\title{
Perspective on Site Selection of Small Modular Reactors
}

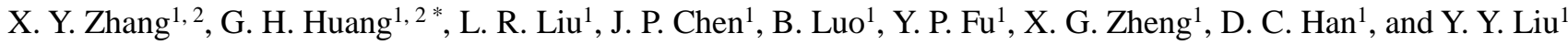 \\ ${ }^{1}$ Faculty of Engineering and Applied Science, University of Regina, Regina, Saskatchewan S4S 0A2, Canada \\ ${ }^{2}$ State Key Joint Laboratory of Environmental Simulation and Pollution Control, China-Canada Center for Energy, Environment and Ecology \\ Research, UR-BNU, School of Environment, Beijing Normal University, Beijing 100875, China.
}

Received 08 March 2020; revised 20 March 2020; accepted 24 March 2020; published online 31 March 2020

\begin{abstract}
As an emerging means of energy supply, small modular reactors (SMRs) are considered as a promising option for relieving environmental pressure caused by increasing fossil fuel consumption. Since SMRs are at an early stage of development, in-depth analysis on the necessity and feasibility of their deployment is essential. The site selection of SMRs, which is a multifaceted process and should be guided by a clearly established set of criteria, is a crucial step. To propose comprehensive recommendations for SMR site selection, a review is provided in this study. The review involves development process, technical characteristics and potential applications of SMRs, research status of SMR site selection, and criteria for site selection of nuclear power plants (NPPs). Different considerations of siting criteria between SMRs and NPPs are analyzed. Based on the review and analyses, perspectives and targeted suggestions on SMR site selection are provided.
\end{abstract}

Keywords: small modular reactor, nuclear power plants, site selection, siting criteria

\section{Introduction}

Nuclear energy, as a carbon-free energy source, plays a crucial role for meeting the world's increasing energy demands, and for relieving environmental pressure caused by increasing fossil fuel consumption. Since nuclear power generation has become established in the 1950s, the size of reactor units has grown from 60 MWe to over 1600 MWe (Kim et al., 2014). Today, due to the high capital input of traditional large power reactors and the need to supply electricity to small grids, there is a trend to develop smaller units of nuclear reactors.

Compared with NPPs, small modular reactors (SMRs) are considered safer, more cost effective, and more flexible, requireing smaller capital input and having shorter construction periods (Vujić et al., 2012). Specifically, SMRs (1) have smaller generation capacities that can better fit for smaller electricity grids and facilitate gradual connection to the grids (Locatelli and Mancini, 2012; Black et al., 2015); (2) require lower upfront capital costs, which can reduce financial risks and would be attractive to private investors even without government intervention (Spencer and Loris, 2011); (3) are factory fabrication which makes the transportation and assembly much easier and can shorten the on-site construction periods (Devanand et al., 2019); (4) have enhanced safety features that make the safe nuclear power technology even safer (Vujić et al., 2012;

${ }^{*}$ Corresponding author. Tel.: 1-306-5854095.

E-mail address: gordon.huang@ uregina.ca (G. H. Huang).

ISSN: 2663-6859 print/2663-6867 online

(C) 2020 ISEIS All rights reserved. doi:10.3808/jeil.202000026.
Buchholz et al., 2015; Butt et al., 2016). There are a number of benefits by developing SMRs. For example, they could help achieve reduction targets of greenhouse gas emissions by replacing fossil fuel-fired power plants; they could provide an effective alternative against future carbon taxes; they could supply heat and power for resource extraction and heavy industry; they could improve the quality of life for people live in remote communities.

However, since SMRs are at an early stage of development, many concerns still need to be addressed. The selection of suitable sites, which is a multifaceted process and includes multiple considerations such as natural conditions, land use, public acceptance and environmental impacts, is a crucial step for its development. Scientific site selection process must be guided by a clearly established set of criteria, with consideration of various attributes. The outcome of the results can in turn significantly affect the construction costs, surrounding environments, public safety and some other aspects over its operating lifetime. At present, the relevant research is limited, which cannot provide a sufficient basis for SMR site selection.

In order to propose comprehensive recommendations for SMR site selection, this paper (1) summerizes the development process, technical characteristics and potential applications of SMRs; (2) reviews the factors for site selection that used in previous studies for nuclear power plant (NPP) site selection in four respects (i.e., natural, socio-economic, environmental and safety factors); (3) analyzes different considerations between SMRs and NPPs when conducting site selection; (4) provides perspectives and targeted suggestions towards each factor for SMR site selection. 


\section{Development of SMRs}

SMRs are generally defined as having electric generating capacity of 300 megawatts (MWe) or less (Egan, 1984) (Figure 1). Several possible applications of SMRs are demonstrated by many researchers. Basically, an SMR from 150 to $300 \mathrm{MWe}$ can be implemented for on- and off-grid power generation to reduce the reliance on fossil fuels, and a smaller one (from 10 to $50 \mathrm{MWe}$ ) is capable of providing heat and power for heavy industry such as resource extraction (Black et al., 2015; Carless et al., 2016; Värri and Syri, 2019). To be specific, due to the potential for facilitating carbon reduction, SMRs have been recognized as an emerging source to provide small-scale highreliability power which can help many regions, especially developing counties, to meet the growing demand for carbon-free energy and promote sustainable economic growth (Terrapon Pfaff et al., 2014). SMRs can also produce high-temperature steam for the industry processes (e.g., for hydrogen production and desalination) (Naterer et al., 2013; Ingersoll et al., 2014; Lindroos et al., 2019).

The development of SMRs can be traced back to nearly the start of nuclear age. The International Reactor Innovative and Secure (IRIS) program (1997 2009) made the first effort to design a compact and integral Pressurized Water Reactors (iPWR). The IRIS project attempted to integrate the separate parts of reactors, like reactor cores, control rods and pressurizer, into a single and compact module (Khan et al., 2010; Ho et al., 2019). Based on the findings of IRIS program, the U.S. Department of Energy provided funds for two i-PWR designs. Babcock and Wilcox received one of the funds and designed $\mathrm{m}$ Power (160 MW), while NuScale Power received the another one and developed NuScale Reactor (60 MW) (Buchholz et al., 2015; Carelli, 2015). Many other projects of SMRs have also been developed in various countries around the world, such as SMART (100 MWe) in South Korea (Park, 2011; Hong and Brook, 2018), ACP-100 (100 MWe) in China (Ramana et al., 2013) and KLT-40S (two units of $35 \mathrm{MWe}$ ) in Russia (Nian and Zhong, 2020).

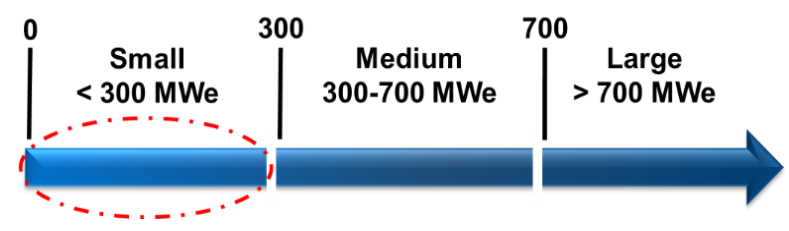

Figure 1. Size of reactor units and definition of SMR.

The design of SMRs are corresponded to all the main reactor categories which include water-cooled reactors, high-temperature gas-cooled reactor, liquid-metal, sodium and gas-cooled reactors with fast neutron spectrum, and molten salt reactors (Locatelli et al., 2013; International Atomic Energy Agency, 2014). From the application point of view, SMRs can also be divided into land-based, immersed and floating reactors. As this emerging technology matures, SMRs have attracted more and more countries' attention, including Argentina, Brazil, Canada, China, France, India, Japan, Republic of Korea, Rus- sian Federation, South Africa, USA, etc. (International Atomic Energy Agency, 2014). There have been more than 40 concepts of SMRs being developed at various stages from conceptual design to prototype construction around the world. A report published by IAEA summarized that the SMRs based on light water reactor were recognized as the most mature technology with lowest risk for the moment (Hong and Brook, 2018; Siegel et al., 2018).

The evolutionary of SMRs could be generally summarize as two aspects: more cost-effective and more secure (Liu and Fan, 2014). A number of institutes and companies were concentrated on how to keep a balance of tradition and innovation to minimize power grade and configuration size of SMRs for less generation and operation cost. For example, Gas Turbine Modular Helium Reactor (GT-MHR) proposed by General Atomics has a 285 MWe capacity, covered by graphite reflector blocks both inside and outside, which can be resistant to the harsh environment and lead to high temperature operating conditions, with 50\% increase of efficiency (Kiryushin et al., 1997). Subsequently, General Atomics developed a smaller version of the GT-MHR with the capacity from 10 to 25 MWe named Remote-Site Modular Helium Reactor (RS-MHR), which could reduce the operation cost and was applicable for remote area (Baldwin et al., 2008). In 2012, Areva developed a new design of reactor called ANTARES (A New Technology Advanced Reactor Energy System) with a 285 MWe prismatic helium cooled design for further reducing the operation cost (Lommers et al., 2012).

In consideration of safety, the elimination of accident initiators and prevention of accident consequences are the main purposes. Various measures were undertaken to improve safety features of SMRs, such as relatively smaller core sizes, larger reactor surface-to-volume ratios and lower core power densities (Liu and Fan, 2014). For example, the NuScale, mPower and Westinghouse-SMR employed iPWR technology to reduce the number and size of penetrations and welding links through the reactor pressure vessel, eradicating the high-consequence risk of a large pipe-break (Buchhol et al., 2015). Some other concepts under test (e.g., ABV-6M and CAREM) are expected to work with natural flow in the fundamental loop, aiming to exclude the failure of the primary cooling pump and pump shift (Dixit et al., 2013; Nian, 2017).

\section{Reviews on NPP Site Selection}

To deploy SMRs as a potential power generation technology, in-depth analyses of its necessity and feasibility is essential. Site selection, which includes multiple considerations such as natural conditions, land use, public acceptance and environmental impacts, is a crucial step. This process will have a significant impact on construction cost, environmental health, public safety and other aspects over its operating lifetime, and the outcome of the results will even affect the success of the whole project. Therefore, it is necessary to conduct a comprehensive and in-depth study on SMR site selection. At present, the research on SMR site selection is limited, which cannot provide a comprehensive and sufficient basis for siting SMRs. However, 
Table 1. Siting Factors Considered in Previous Studies

\begin{tabular}{|c|c|c|c|}
\hline Attribute & Criteria & Attribute & Criteria \\
\hline Natural factors & $\begin{array}{l}\text { - Geographical and geological factors } \\
\text { Earthquakes/seismicity } \\
\text { Volcanism } \\
\text { Cooling water availability } \\
\text { Characteristics of subsurface material } \\
\text { Properties of subsurface strata/depth } \\
\text { Topography and slope } \\
\text { Inland and coastal location } \\
\text { - Meteorological factors } \\
\text { Wind } \\
\text { Temperature } \\
\text { Precipitation } \\
\text { Atmospheric stability } \\
\text { Hydrology } \\
\text { Extreme events }\end{array}$ & $\begin{array}{l}\text { Environmental } \\
\text { factors }\end{array}$ & $\begin{array}{l}\text { - Radiological related } \\
\text { Terrestrial ecosystem } \\
\text { Aquatic ecosystem } \\
\text { Human health } \\
\text { - Non-radiological related } \\
\text { Terrestrial ecosystem } \\
\text { Aquatic ecosystem } \\
\text { Human health } \\
\text { Environmental sensitivity } \\
\text { Natural reserves } \\
\text { Agriculture and farming/land use } \\
\text { Drinking water source } \\
\text { Pollutant emission reduction benefits } \\
\text { Distance from water body } \\
\text { Thermal pollution }\end{array}$ \\
\hline $\begin{array}{l}\text { Socio-economic } \\
\text { factors }\end{array}$ & $\begin{array}{l}\text { - Social factors } \\
\text { Public acceptance } \\
\text { Population distribution } \\
\text { Energy demand } \\
\text { Proximity to national borders } \\
\text { Tourism and recreation } \\
\text { - Economic factors } \\
\text { Construction cost } \\
\text { Availability of the land } \\
\text { Proximity to electrical grid } \\
\text { Regional development incentives } \\
\text { Proximity to major load center } \\
\text { Distance from industry center } \\
\text { Financial risks }\end{array}$ & Safety factors & $\begin{array}{l}\text { - Proximity to hazardous facilities } \\
\text { Airports } \\
\text { Military installations } \\
\text { Chemical plants } \\
\text { Mining } \\
\text { Gas pipeline } \\
\text { Wastewater treatment plant } \\
\text { Industry } \\
\text { External human accidents } \\
\text { Constructions } \\
\text { - Safety of surroundings } \\
\text { Dispersion of radioactive material } \\
\text { Evacuation routes and access routes } \\
\text { Spent nuclear fuel } \\
\end{array}$ \\
\hline
\end{tabular}

there have been many studies on other types of nuclear installations, such as underground nuclear facilities (Watson et al., 1975; Kroger, 1976), offshore nuclear facilities (Klepper and Anderson, 1974; Kindt, 1980), nuclear waste storage (Hatch, 1992; McCreath and Diederichs, 1994) and traditional NPPs (Salih et al., 2018; Tromans et al., 2019), which can serve as references. Since the reactors in traditional NPPs has the highest similarity with SMRs in terms of designs and applications, NPP-siting related studies can serve as key references for SMR siting. In this study, the factors considered in previous studies for NPP site selection are reviewed comprehensively. These factors can be divided into four groups, which are natural, socio-economic, environmental and safety factors. Eighty eight related papers were reviewed. The siting factors considered in previous studies and their distributions are presented in Table 1 and Figure 2.

\subsection{Natural Factors}

When conducting NPP siting, natural factors, which is related to the safety, cost and feasibility of the NPP installation and operation, are inevitable to be considered. For instance, the natural factors which are commonly considered as safety criteria for NPP siting include earthquakes, temperature, precipita- tion, flooding, volcanism, etc.

In general, natural factors include geographical and geological factors, as well as meteorological factors. Among the geographical and geological factors, one of the most significant features in NPP site selection is to avoid areas of tectonic disturbances caused by seismic activities (e.g., faults, fractures, crustal movements and strike) (Keeney and Nair, 1977). Particularly, Adam and Vero (1990) proposed a telluric-based magnetotelluric soundings approach to deal with the localization of tectonic disturbances based on experimental and modeling analysis, the application of which was utilized in NPP site selection. Kutbi (1987) took seismology factors (i.e., position of conceivable epicenters, the depth of the seismic focus, the energy of the anticipated seismic incidents and their relationship with the active tectonics) as basic criteria of NPP siting in Saudi Arab and examined two potential siting areas (i.e., Jeddah region and Dhahram region). In addition to the factors mentioned above, other geographical and geological factors, such as distance from volcanism activate areas, access to available cooling water, characteristics of subsurface material, properties of subsurface strata, depth and type of bed rock, topography and slope, inland and coastal location, have also been evaluated (Rouhiainen, 1987; Yu et al., 2011; Bo et al., 2013; Abudeif et al., 2015; Basri et al., 2016; Wu et al., 2020). For 
example, enough water resources must be provided for the cooling systems of the NPP during both the operation period and shutdown (Wu et al., 2020). Ahmed et al. (1979) considered different characteristics of cooling water, which include sources, availability, distance and incremental water temperature.

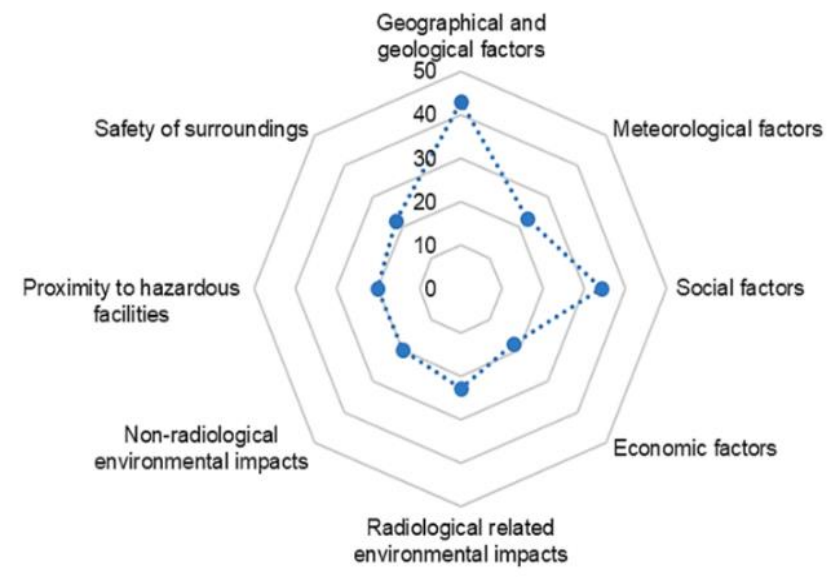

Figure 2. Distribution of siting factors considered in previous studies.

From the perspective of meteorology, a number of other factors, including temperature, wind speed, rainfall, humidity, atmospheric stability and extreme events, should be considered for NPP siting (Hu et al., 1998; Karameldin and Mekhemar, 2001; Basu, 2019). For instance, Ahmed et al. (1979) proposed a methodology to facilitate the selection of the optimal sites among alternate suitable sites for a nuclear power station, taking flooding risks into account. Karameldin and Mekhemar (2001) carried out detailed research towards average temperature, wind speed, rainfall and humidity for four potential sites and provided recommendations for each factor. Additionally, the severity influenced by the extreme meteorological phenomenon such as hurricane, hail and extreme precipitation also need to be considered as NPP siting criteria. The location that influenced less by the extreme climate events will be given higher priority (Bo et al., 2013; Basu, 2019).

\subsection{Socio-Economic Factors}

Socio-economic factors play important roles in harmonious development of a region. Thus, when siting NPP, socioeconomic factors such as public acceptance, population density, construction cost, transmission cost and transportation cost should be considered.

The public acceptance of nuclear power exists ongoing controversy over the world (Tanaka, 2004). There are serious social problems due to lack of public acceptance for nuclear power in many countries (Clark et al., 1997; GlobeScan, 2005; Macintosh, 2007; Greenberg, 2009), and public opposition is a major obstacle to the construction of NPP (Sun et al., 2014; Wu et al., 2020). Therefore, it is critical to know the public prefer- ences and to understand the reasons. Generally, the candidate NPP site with higher public acceptance is more suitable. Numerous surveys related to public preferences for nuclear power have been conducted (Ahmed et al., 1979; Karameldin and Mekhemar, 2001; Tanaka, 2004; Macintosh, 2007; Greenberg, 2009; Wu et al., 2020). For example, Tanaka (2004) conducted a survey with 1000 randomly selected adults in Japan for studying public acceptance in regard to the siting of NPP. Greenberg (2009) conducted a survey involving 2101 adults who lived within 50 miles of 11 existing major NPP sites and 600 adults who lived elsewhere in the U.S. for investigating the public attitudes in selecting the NPP sites.

The site evaluation of the NPPs should consider the distribution and characteristics of regional population density. Generally, NPP sites should be located away from densely populated centers for preventing any radioactive hazard to humans (Commission, 1975; Agency, 2002; Basri et al., 2016; Damoom et al., 2019; Wu et al., 2020). Considering this reason, NPP-site areas are divided into exclusion zone and low population zone (i.e., immediate neighborhood of the exclusion zone) (Turner, 2002; Damoom et al., 2019). According to the research associated with the selection of NPP sites conduced by Damoom et al. (2019), the population density of the areas for NPP sites should below 193 people per square kilometer.

Construction or engineering cost related to the NPP siting has also been taken into consideration in many researches (Wang et al., 2013; Abudeif et al., 2015; Wu et al., 2020). Among them, Wu et al. (2020) emphasized that the construction cost is mostly with respect to land, material, labor, and other related costs, which vary from location to location; candidate NPP sites with a lower cost are more desired. Wang et al. (2013) suggested that the engineering cost, such as land expropriation compensation, immigrants and remove, resulting from the site characteristics should be considered in selecting the candidate sites.

Transmission cost is another economic factor that is usually considered, which includes not only the cost of supporting facilities for transmission, but also the cost from power loss in the transmission. This is a key factor that has been considered by many researchers when selecting the NPP sites (Wang et al., 2013; Abudeif et al., 2015; Baskurt and Aydin, 2018; Wu et al., 2020). For instance, Baskurt and Aydin (2018) thought it would be costly and time-consuming to establish a new transmission grid for building NPP in Edirne, Turkey, and suggested that siting NPP near the existing transmission grid would have a practical benefit; Wang et al. (2013) recommended that, in addition to close to power grid and load center, being compatible with the connecting grid in order to ensure the operational stability under different conditions would be necessary.

The transportation cost should not be ignored during the selection of NPP sites. This factor is primarily affected by transportation routes, especially in transporting the heavy equipment and nuclear fuel to the plant, and conveying the solid waste to the storage sites (Huang et al., 1997; Wang et al., 2013; Baskurt and Aydin, 2018; Wu et al., 2020). Wang et al. (2013) proposed that the cost related to the transportation of spent 
nuclear fuel and solid waste should be estimated in selecting candidate NPP sites. Wu et al. (2020) considered the transportation cost of nuclear fuel supply and advised that the candidate NPP sites with convenient nuclear supply should have higher priorities.

\subsection{Environmental Factors}

In the site selection for NPPs, the environmental compatibility is a significant factor, which includes the radiological and non-radiological impacts to the surrounding environmental conditions (e.g., human health, terrestrial ecosystem, aquatic ecosystem and natural reserves) (IAEA, 2012). The environmental conditions should meet the construction and operation requirements for processing the plant, and the potential shortand long-term impacts on surrounding environments should also be considered at NPP siting stage. Usually, the environmenttal factors entails the feature of atmospheric diffusion conditions, water diffusion conditions, population distributions, landuse situations, etc. (Watson and Gamertsfelder, 1963; Wang et al., 2013).

Radioactive impacts of the operation of NPPs and treatment of spared wastes are key factors considered in site selections. Radiological contamination is the deposition of, or presence of radioactive substances on surfaces or within solids, liquids or gases (including the human being), where their presence is unintended or undesirable. Airborne radioactive particles may emit alpha, beta, gamma or neutron radiation, depending on the radioisotope present (Zhang et al., 2014). Margulies (2004) studied the perceived radiological risks in additional nuclear units primarily in the middle Atlantic and northeastern United States of American. Atmospheric diffusion conditions should be considered and compared based on the wind directions and atmospheric characteristics. Radiological air contamination were assessed for selected places at Al-Tuwaitha nuclear site during winter and spring (Salih et al., 2018). The collected samples were analyzed for gross alpha/beta radioactivity using Ludlum model 3030 and measurement particles activeity in Al Tuwaitha nuclear site and the surrounding areas. Water diffusion condition will also be taken into account, which includes surface water and underground water conditions (Maqsood et al., 2005; Tan et al., 2011). Affecting upstream of drinking water sources should be avoided under both normal circumstances and accidents. The tritium concentrations were measured in drainage systems at Tokaimura NPP in Japan by Miyamoto et al., (2002). Basri et al., (2016) investigated the dispersion and dilution capabilities and potential contamination pathways of the groundwater environment under operating and accident conditions with respect to present and future uses of water sources.

The nonradioactive influences, such as the influences by the construction and operation of NPPs on aquatic ecosystem, terrestrial ecosystem, human health, and the climate or microclimate affected by the cooling tower to surrounding region (i.e., humidity, flood and mist, freezing, visibility and diffusions, etc.) are other kinds of environmental factors that need to be considered. In general, the environmental risks were used as constraints and provide an inherent optimized safety margin in the selection of sites. The land-use types, such as farmland, natural reserves, tourist zone, as well as future development of regional planning should be considered as well (Weng et al., 2010). Barzehkar et al. (2016) focuses on environmental capability evaluation for the NPP site selection in the coastal area of Gilan Province (Sahar Khiz), Iran. Multiple environmental parameters (e.g., physical factors: slop, distance from fault, flooding, distance from water resources, distance from sea; and biological factors: distance from protected areas, land use) have been considered, and Boolean logic and fuzzy logic based on WLC were used to identify four sites in the coastal areas of Egypt (Huang et al., 1996; Cai et al., 2007; Li et al., 2010). NPPs require enormous cooling water, which is discharged into the terrestrial and aquatic environments routinely. Although it is pointed out that the discharge limit for NPP was stringent enough to not harm the quartic and terrestrial environment (Khattak et al., 2017), radiological related factors should also be taken into account when siting NPPs. Hartog et al. (1989) considered consequences for the environment of water systems as a criteria to locate nine alternative sites in Netherlands based on Advisory Council for Physical Planning (RARO).

\subsection{Safety Factors}

Due to the large amount of nuclear fuel and highly radioactive sources involved, the safety of NPPs is always a controversial and crucial issue (Basri et al., 2016). To improve the safety of NPPs, site location can be readily manipulated and is under the direct control of the safety authorities and the reactor operator (Openshaw, 1984). Therefore, when selecting the location of NPPs, safety related criteria are widely adopted as either rejection criteria or selection criteria. The fundamental safety objective can be divided into two perspectives: (1) to protect individuals, public, and the surroundings against the harmful effects of radiation (IAEA, 2006); and (2) to protect NPPs from the potential hazardous facilities (IAEA, 2006).

According to the standards and guidelines documented by IAEA, assessments of radiological hazards from the plant to the surroundings during normal operation and in abnormal conditions were necessary. It is illustrated that both immediate and long-term radiological effects from various radiological scenarios should be taken into account (IAEA, 2006). For example, Keeney and Nair considered radiation exposure by measuring the distance from populated areas (Keeney and Nair, 1977). When screening potential sites, areas should be more than 3 miles from populated places that have more than 2500 people and 1 mile from populated places that have less than 2500 people. In the UK, both the Central Electricity Generating Board (CEGB) and the Health and Safety Executive (HSE) shared a common safety philosophy to minimize the radiological consequences of any accident through taking all reasonably practicable actions (HSE, 1979). In Switzerland, the environs of the nuclear facilities were constantly monitored by local networks of ground radiation detectors and thermoluminescence dose detectors. Moreover, the surrounding regions were surveyed biannually to detect any releases, to establish baseline information, 
to monitor the doserate distribution and to determine the variation of natural radiation (Rybach et al., 2001). Specially, emergency plans or evacuation plans are required to provide protection and countermeasures in case of accidents or radiological events in NPPs. The emergency plan in the plant must be compatible with the emergency plan outside of the plant in order to ensure optimum protection for the public and the environment (IAEA, 2006). For example, the development of nuclear power was expected to increase due to the increasing demand of electrical energy. Sites where emergency plans were not feasible would be rejected in the first round selection (Abudeif et al., 2015). Moreover, under the changing climatic conditions, several safety problems were proposed, including loss of off-site power, communication failure, restriction of evacuation routes, equipment malfunction, and Unplanned shutdowns (Kopytko and Perkins, 2011). In the future, how to consider the abovementioned climate change related safety issues in the site selection of NPPs deserves further investigations.

To protect NPPs from the potential hazardous facilities (e.g., airports, military installations, refineries, chemical plants and petroleum product storage installations) is another key perspective (International Atomic Energy Agency, 2002). Potential accidents could create dangerous substances, which endanger the safety of NPPs (Ahme et al., 1979; Wu et al., 2020). The IAEA has set specific buffer zones for the potential hazardous facilities. The NPP should be $16 \mathrm{~km}$ away from airports and $5 \mathrm{~km}$ away from petrochemicals (International Atomic Energy Agency, 2015). According to the specific study region, differ-ent hazardous facilities have been considered in the previous studies. For example, Baskurt and Aydin developed an ap-proach to reveal suitable areas in Edirne, Turkey with a consi-deration of pipelines, roads, railways, airports and other indus-trial investments (Baskurt and Aydin, 2018). In Israel, nuclear power was considered as one of the possible energy resources capable of solving the energy shortage problem. In the study of NPP site selection, small to medium size military bases were excluded as the limitation zones (Yaar et al., 2016). In the study of Sahar Khiz Region in Gilan Province, Iran, the NPPs were selected by taking gas pipeline, wastewater treatment, industry, and mine into consideration. Also, the distance from these faci-lities were set as $8 \mathrm{~km}$ (Barzehkar et al., 2016). Besides the in-dustrial facilities, external human accidents have great impacts on the safety of NPPs. In the regional analysis, the site near to large dangerous facilities, huge airport, or transporttation routes for mass dangerous materials should be negated (Wang et al., 2013).

\section{Suggestions on SMR Site Selection}

As mentioned above, the research on SMR site selection is very limited, and most of the research is conducted from specific aspects, such as geographical structure, cost effectiveness, public acceptance and power grid stability. For example, Carl and James (2012) recommended that the nuclear facility should be built on bedrock, taking the advantage of favorable geotechnical properties. Kessides (2012) and Kunz et al. (2012) considered natural disasters (i.e., earthquake and tsunami) and explored the corresponding possible impacts on the surrounding environments. Shrestha et al. (2018) studied the appropriate siting location by considering electric and non-electric loads, existing and decommisioned generation, transmission lines and switching stations. Poudel et al. (2018) suggested that when considering the feasibility of nuclear reactors, the government's fiscal capacity and power grid capacity policies also need to be considered, and the location of reactors could be determined through social surveys and analysis of existing policies. Almalki et al. (2019) gave SMR siting recommendations based on geographical considerations. In this section, the different considerations of siting criteria between SMRs and NPPs are analyzed and targeted suggestions towards each factor for SMR site selection are provided.

In terms of natural factors, all the nuclear installations are vulnerable to the abovementioned geographical, geological and meteorological criteria, SMRs are no exception (Reyes, 2012). However, with its advanced structural designs and enhanced safety features (Harman et al., 2011; Reyes, 2012; Kim et al., 2016; Ford et al., 2017; Udiyani et al., 2018), SMRs are likely to be safer and more reliable compared with traditional NPPs. A quantity of researches have been conducted to study its safety features in response to potential disasters, the aim of which is to ensure a high level of safety and security for SMR designs (Reyes, 2012; Butt et al., 2016; Liao et al., 2016). For example, the reduced pipelines in SMR systems can prevent several design-basis accidents such as loss-of-coolant-accident (Kim et al., 2016). The NuScale design used advanced passive safety systems to provide long-term cooling for the case of a complete station blackout that caused by extreme events (Reyes, 2012). Nevertheless, because of the potential hazards for all kinds of nuclear installations, geological factors such as seismicity and volcanism, and meteorological factors such as tornadoes, tsunamis and flooding also need to be considered when siting SMRs. Thus, it is suggested to follow the same standards as NPPs for this kind of factors when conducting site selection for SMRs.

As for socio-economic factors, the abovementioned factors should also be taken into account when siting SMRs. To be specific, one of the potential applications for SMRs is for remote or less developed communities where large electricity capacities are not necessary, such as for the Arctic regions in Canada, the U.S. and Russia (Lokhov et al., 2013). The acceptance of these areas is crucial. However, according to Sam-Aggrey (2016), aboriginals, who live in northern Canada, are more likely than other Canadians to have a negative perception for developing SMRs. Thus, it is suggested that science promotion activities should be carried out in remote areas to promote the benefits and advantages of developing SMRs. In addition, as for the factor of population density, high-density population should also be avoided in comparing and selecting candidate sites. However, SMRs can be built relatively close to populartion areas to minimize the cost of service transmission due to its lower radiation and explosion risks compared with NPPs (Lyman, 2013; Almalk et al., 2019). In terms of economic factors, when siting SMRs, costs such as the capital cost and trans- 
mission cost will also need to be evaluated (Boarin and Ricotti, 2014; Shrestha et al., 2018; Almalki et al., 2019). According to Lokhov et al. (2013), compared with traditional NPPs, twenty percent of the capital cost of SMRs will be saved because of the shorter construction period. As a result, SMRs are suitable to be introduced into the economically less developed areas. Moreover, SMR locations have relatively low requirements for transportation, because SMRs are factory fabrication and there is no need to convey the heavy materials during the construction period (Devanand et al., 2019).

In addition, considerable efforts have been done in examining the environmental threats introduced by the construction and operation of NPPs. These threats can be divided into two aspects (i.e., radiological related impacts and non-radiological impacts) and can not be overlooked when conducting site selection for NPPs. As for SMRs, a number of studies were concerned with such issues. For example, Shirvan et al. (2016) compared five nuclear power technologies, giving more focus to iPWR, in terms of their environmental performance. Carless et al. (2019) adopted nuclear containment decontamination factors to estimate radioactivity in the environment to help determine the size of emergency planning zones for SMRs. However, there is lack of comprehensive and quantified comparisons between traditional NPPs and SMRs in the respect of environmental impacts. Thus, when siting SMRs, the radiological related impacts on terrestrial ecosystem, aquatic ecosystem and human health, and non-radiological impacts on the surrounding environments should be emphasized as well. In addition, the land use of a power plant is related to its type and capacity (Devanand et al., 2019). According to Devanand et al. (2019), a single unit of SMR with 100 MWe and 225 MWe capacity require about 21000 and $61000 \mathrm{~m}^{2}$, respectively. Other studies also pointed out that SMRs needed less area than NPPs because of its smaller size (Alonso et al., 2016; Vegel and Quinn, 2017; Mignacca et al., 2018). This feature has a direct effect on the site selection of SMRs since the smaller footprints of it can open up more potential suitable sites (Almalk et al., 2019).

Last but not least, the safety factor is also one of the most important indicators that must be considered when choosing suitable sites for SMRs. Due to the compact size, small capacity and passive safety design of commercial SMRs (Kim et al., 2016; Liao et al., 2016), the potential radiation hazard of SMRs is relatively lower than that of NPPs. The negative effects of potential hazardous facilities on SMRs are also low. Moreover, SMRs are currently in the development stage, and many studies evaluated the safety of SMRs through modelling or experimental methods. For example, the postulated large break lossof-coolant accident (LOCA) safety of the Westinghouse-SMR was examined by an evaluation model, and the results showed that small break LOCA was the most limiting design basis accident (Liao et al., 2016). The passive safety systems of multi-application small light water reactor (MASLWR) have been assessed through the RELAP5 Mod 4.0 system analysis code by Butt et al. (2016). However, the existing studies mainly focus on the passive safety design of SMRs when studying its safety and few works studied the relationship between these safety features and the site selection preference. Since safety is of great importance for all kinds of nuclear installations, the standard for SMR siting in this respect is recommended to be the same as that of regular NPPs.

\section{Conclusion}

Site selection is a crucial step for introducing SMRs into a regional energy system. This process includes several steps, among which the identification of dominant factors is of great significance and is mainly reviewed in this paper. To be specific, in this study: the development process, technical characteristics and potential applications of SMRs are summarized; dominant factors that considered in previous studies for NPP site selection in four respects are reviewed; the differences between SMRs and NPPs are analyzed; perspectives and targeted suggestions on SMR site selection are provided.

However, many of the SMRs are at the early design stage and full data needed for guiding site selection are still unavailable. As a result, all the factors analyzed in this study are described qualitatively. In present period, to obtain more detailed numerical values of each specific factor, more targeted research such as the amount of radioactivity being released into the environment and cooling water consumption per unit of power generation should be studied. In addition, as mentioned above, there are more than 40 designs of SMRs being developed at various stages around the world with multiple potential applications. Thus, by taking the factors summarized in this study into consideration, decisions should be made according to each specific matter when siting SMRs.

Acknowledgments. This research was supported by the National Key Research and Development Plan (2016YFA0601502) and the Sylvia Fedoruk Canadian Centre project for Nuclear Innovation.

\section{References}

Abudeif, A.M., Abdel Moneim, A.A., and Farrag, A.F. (2015). Multicriteria decision analysis based on analytic hierarchy process in GIS environment for siting nuclear power plant in Egypt. Annals of Nuclear Energy. Elsevier Ltd, 75, 682-692. https://doi.org/10. 1016/j.anucene.2014.09.024

Agency, I.A.E. (2002). Dispersion of Radioactive Material in Air and Water Consideration of Polulation Distribution in Site Evaluation for Nuclear Power Plants: Safety Guide. International Atomic Energy Agency.

Ahmed, S., Husseiny, A.A., and Cho, H.Y. (1979). A formal methodology for acceptability analysis of alternate sites for nuclear power stations. Nuclear Engineering and Design, 51(3), 361-388. https://doi.org/10.1016/0029-5493(79)90125-0

Almalki, R., Piwowar, J., and Siemer, J. (2019). Geographical considerations in site selection for small modular reactors in Saskatchewan. Geosciences. 9(9), 1-20. https://doi.org/10.3390/geoscien ces 9090402

Alonso, G., Bilbao, S., and Valle, E. (2016). Economic competitiveness of small modular reactors versus coal and combined cycle plants. Energy, 116, 867-879. https://doi.org/10.1016/j.energy.2016. 10.030

Baldwin, D., Campbell, M., Ellis, C., Richards, M., and Shenoy, A. (2008). MHR design, technology and applications, Energy conversion and management. Energy conversion and management, 49(7), 1898-1901. https://doi.org/10.1016/j.enconman.200 7.07.048 
Barzehkar, M., Dinan, N.M., and Salemi, A. (2016). Environmental capability evaluation for nuclear power plant site selection: a case study of Sahar Khiz Region in Gilan Province, Iran. Environmental Earth Sciences, 75(12), 1-15. https://doi.org/ 10.1007/s12665-0165825-9

Baskurt, Z.M. and Aydin, C.C. (2018). Nuclear power plant site selection by Weighted Linear Combination in GIS environment. Progress in Nuclear Energy, 104, 85-101. https://doi.org/10.1016/ j.pnucene.2017.09.004

Basri, N.A., Hashim, S., Ramli, A.T., Bradley, D.A., and Hamzah, K. (2016). Regulatory requirements for nuclear power plant site selection in Malaysia-a review. Journal of Radiological Protection, 36(4), 96-111. https://doi.org/10.1088/095 2-47 46/36/4/R96

Black, G., Black, M.A.T., Solan, D., and Shropshire, D. (2015). Carbon free energy development and the role of small modular reactors: A review and decision framework for deployment in developing countries. Renewable and Sustainable Energy Reviews, 43, 83-94. https://doi.org/10.1016/j.rser.2014.11.011

Boarin, S. and Ricotti, M.E. (2014). An evaluation of SMR economic attractiveness. Science and Technology of Nuclear Installations, 2014(i). https://doi.org/10.1155/2014/803698

Buchholz, S., Krüssenberg, A.K., and Schaffrath, A. (2015). Study of safety and international development of small modular reactors (SMR). International Topical Meeting on Nuclear Reactor Thermal Hydraulics 2015, Nureth 2015, 3(11), 2427-2440.

Butt, H.N., Ilyas, M., Ahmad, M., and Aydogan, F. (2016). Assessment of passive safety system of a Small Modular Reactor (SMR). Annals of Nuclear Energy, 98, 191-199. https://doi.org/10.1016/j.anucene. 2016.07.018

Cai, Y.P., Huang, G.H., Nie, X.H. Li, Y.P., and Tan, Q. (2007). Municipal solid waste management under uncertainty: a mixed interval parameter fuzzy-stochastic robust programming approach. Environmental Engineering Science, 24(3), 338-352. https://doi. org/10.1089/ees.2005.0140

Carelli, M.D. (2015). Integral pressurized-water reactors (iPWRs) for producing nuclear energy: a new paradigm. Handbook of Small Modular Nuclear Reactors, 61-75. https://doi.org/10.1533/9780857 098535.1.61

Carl, W.M., and James, M.M. (2012). Underground Siting of Small Modular Reactors in Bedrock: Rationale, Concepts, and Applications. Small Modular Reactors Symposium, 183-192. https://doi. org/10.1115/SMR2011-6652

Carless, T.S., Griffin, W.M., and Fischbeck, P.S. (2016). The environmental competitiveness of small modular reactors: A life cycle study. Energy, 114, 84-99. https://doi.org/10.1016/j.energy. 2016.07.111

Carless, T.S., Talabi, S.M., and Fischbeck, P.S. (2019). Risk and regulatory considerations for small modular reactor emergency planning zones based on passive decontamination potential. Energy, 167, 740-756. https://doi.org/10.1016/j.energy.2018.1 0.173

Clark, D.E., Michelbrink, L., Allison, T., and Metz, W.C. (1997). Nuclear power plants and residential housing prices. Growth and Change, 28(4), 496-519. https://doi.org/10.1111/j.1468-2257.1997. tb00990.x

Commission, N.R. (1975). General site suitability criteria for nuclear power stations. Nuclear Regulatory Commission.

Damoom, M.M., Hashim, S., Aljohani, M.S., Saleh, M.A., and Xoubi, N. (2019). Potential areas for nuclear power plants siting in Saudi Arabia: GIS-based multi-criteria decision making analysis. Progress in Nuclear Energy, 110, 110-120. https://doi.org/10.1016/ j.pnucene.2018.09.018

Devanand, A., Kraft, M., and Karimi, I.A. (2019). Optimal site selection for modular nuclear power plants. Computers and Chemical Engineering, 125, 339-350. https://doi.org/10.1016/j.compchemeng. 2019.03.024

Dixit, A., Hibiki, T., Ishii, M., Tanimoto, K., Kondoh, Y., and Hibi, K. (2013). Start-up transient test simulation with and without void-re- activity feedback for a two-phase natural circulation reactor. $\mathrm{Nu}$ clear Engineering and Design, 265, 1131-1147. https://doi.org/ 10.1016/j.nucengdes.2013.08.069

Egan, J.R. (1984). Small reactors and the "second nuclear era". Energy, 9(9-10), 865-874. https://doi.org/10.1016/0360-544 2(84)90017-3

Ford, M.J., Abdulla, A., and Morgan, M.G. (2017). Evaluating the cost, safety, and proliferation risks of small floating nuclear reactors. Risk Analysis, 37(11), 2191-2211. https://doi.org/10.1111/ risa.127 56

GlobeScan (2005). Global public opinion on nuclear issues and the IAEA.

Greenberg, M.R. (2009). NIMBY, CLAMP, and the location of new nuclear-related facilities: U.S. national and 11 site-specific surveys. Risk Analysis, 29(9), 1242-1254. https://doi.org/10.1111/j.1539-69 24.2009.01262.x

Harman, N.F., Anderson, G.S., Lillington, J.N., and Booler, R.V. (2011). Safety assessment principles applied to small modular reactors. Small Modular Reactors Symposium, SMR 2011, 359-368. https://doi.org/10.1115/SMR2011-6580

Hartog, J.A., Hinloopen, E., and Nijkamp, P. (1989). A sensitivity analysis of multicriteria choice-methods. Energy Economics, 11(4), 293-300. https://doi.org/10.1016/0140-9883(89)90045-5

Hatch, M. (1992). Childhood leukemia around nuclear facilities: a commentary. Science of the Total Environment, 127(1-2), 37-42. https://doi.org/10.1016/0048-9697(92)90466-6

Ho, M., Obbard, E., Burr, P.A., and Yeoh, G. (2019). A review on the development of nuclear power reactors. Energy Procedia, 160, 459466. https://doi.org/10.1016/j.egypro.201 9.02.193

Hong, S., and Brook, B.W. (2018). Economic feasibility of energy supply by small modular nuclear reactors on small islands: Case studies of Jeju, Tasmania and Tenerife. Energies, 11(10). https:// doi.org/10.3390/en11102587

Huang, G.H., Cohen, S.J., Yin, Y.Y., and Bass, B (1996). Incorporation of inexact dynamic optimization with fuzzy relation analysis for integrated climate change impact study. Journal of Environmental Management, 48(1), 45-68. https://doi.org/10.1006/jema.1996.0065

Huang, G.H., Baetz, B.W., Patry, G.G., and Terluk, V. (1997). Capacity planning for an integrated waste management system under uncertainty: A North American case study. Waste Management and Research, 15(5), 523-546. https://doi.or g/10.1006/wmre.1996.0106

Health and Safety Executive (HSE) (1979). Safety Assessment Principles for Nuclear Power Reactors.

IAEA, (2006). IAEA Nuclear Energy Series Managing Siting Activities for Nuclear Power Plants.

Ingersoll, D.T., Houghton, Z.J., Bromm, R., and Desportes, C. (2014). NuScale small modular reactor for Co-generation of electricity and water. Desalination, 340, 84-93. https://doi.org/10.1016/j.desal. 2014.02.023

International Atomic Energy Agency (2014). Advances in Small Modular Reactor Technology Developments.

International Atomic Energy Agency (2002). External Human Induced Events in Site Evaluation for Nuclear Power Plants.

International Atomic Energy Agency (2006). Fundamental Safety Principles, Safety Fundamentals.

International Atomic Energy Agency (2015). Site Survey and Site Selection for Nuclear Installations.

Karameldin, A. and Mekhemar, S. (2001). Siting assessment of a water-electricity cogeneration nuclear power plant in Egypt. Desalination, 137(1-3), 45-51. https://doi.org/10.1016/S0011-9164(01) 00203-X

Keeney, R.L. and Nair, K. (1977). Nuclear siting using decision analysis. Energy Policy, 5(3), 223-231. https://doi.org/10.1016/ 0301-4215(77)90038-6

Kessides, I.N. (2012). The future of the nuclear industry reconsidered: Risks, uncertainties, and continued promise. Energy Policy, 48, 185-208. https://doi.org/10.1016/j.enpol.2012.05.008

Kröger, W., Altes, J., and Schwarzer, K. (1976). Underground siting of 
nuclear power plants with emphasis on the "Cut-And-Cover" technique. Nuclear Engineering and Design, 38, 207-227. https:// doi.org/10.1016/0029-5493(76)90097-2

Kim, K.K., Lee, W., Choi, S., Kim, H.R., and Ha, J. (2014). SMART: The first licensed advanced integral reactor. Journal of Energy and Power Engineering, 8(1), 94-102. https://doi.org/10.17265/ 19348975/2014.01.011

Kim, K.M., Jeong, Y.S., Kim, I.G., and Bang, I.C. (2016). Development of passive in-core cooling system for nuclear safety using hybrid heat pipe. Nuclear Technology, 196(3), 598-613. https:// doi.org/10.13182/NT16-32

Khan, S.U.D., Peng, M., Zubair, M., and Wang, S. (2010). A review on specific features of small and medium sized nuclear power plants. International Conference on Nuclear Engineering, 6, 65-77. https:// doi.org/10.1115/ICONE18- 29399

Khattak, M.A., Umairah, A., Rosli, M.A.M., Sabri, S., Saad, M.A., Hamid, M.S.A., and Kazi, S. (2017). Siting consideration for nuclear power plant: A review. Open Science Journal, 2(3), 1-21. https://doi.org/10.23954/osj.v2i3.1078

Kindt, J.W. (1980). Offshore siting of nuclear power plants. Ocean Development and International Law, 8(1), 57-103. https://doi.org/ 10.1080/00908328009545644

Kiryushin, A.I., Kodochigov, N.G., Kouzavkov, N.G., PonomarevStepnoi, N.N., Gloushkov, E.S., and Grebennik, V.N. (1997). Project of the GT-MHR high-temperature helium reactor with gas turbine. Nuclear Engineering and design, 173(1-3), 119-129. https:// doi.org/10.1016/S0029-5493(97)00099-X

Klepper, O.H. and Anderson, T.D. (1974). Siting considerations for future offshore nuclear energy stations. Nuclear Technology, 22(2), 160-169. https://doi.org/10.13182/NT74-A31399

Kutbi, I. I. (1987). A pragmatic pairwise group-decision method for selection of sites for nuclear power plants. Nuclear Engineering and Design, 1987(100), 49-63. https://doi.org/10.1016/00295493(87)90 071-9

Kunz, J.F., Mahar, J.M., Giraud, K.M., and Myers, C.W. (2012). Underground siting of nuclear power plants - Insights from Fukushima. International Conference on Nuclear Engineering, Proceedings, ICONE, 2(1), 449-455. https://doi.org/10.1115/ICONE 20-POWER2012-54945

Li, Y.F., Li, Y.P., Huang, G.H., and Chen, X. (2010). Energy and environmental systems planning under uncertainty-An inexact fuzzy-stochastic programming approach. Applied Energy, 87(10), 3189-3211. https://doi.org/10.1016/j.apenergy.2010.02.030

Liao, J., Kucukboyaci, V.N., and Wright, R.F. (2016). Development of a LOCA safety analysis evaluation model for the Westinghouse Small Modular Reactor. Annals of Nuclear Energy, 98, 61-73. https://doi.org/10.1016/j.anucene.2016.07.023

Lindroos, T.J., Pursiheimo, E., Sahlberg, V., and Tulkki, V. (2019). A techno-economic assessment of NuScale and DHR-400 reactors in a district heating and cooling grid. Energy Sources, Part B: Economics, Planning, and Policy. Taylor \& Francis, 14(1), 13-24. https://doi.org/10.1080/15567249.2019.1595223

Liu, Z. and Fan, J. (2014). Technology readiness assessment of Small Modular Reactor (SMR) designs. Progress in Nuclear Energy, 70, 20-28. https://doi.org/10.1016/j.pnucene.2013. 07.005

Locatelli, G., and Mancini, M. (2012). A framework for the selection of the right nuclear power plant. International Journal of Production Research, 50(17), 4753-4766. https://doi.org/10.1080/ 00 207543.2012.657965

Locatelli, G., Mancini, M., and Todeschini, N. (2013). Generation IV nuclear reactors: Current status and future prospects. Energy Policy, 61, 1503-1520. https://doi.org/10.1016/j.enpo 1.2013.06.101

Lokhov, A., Cameron, R., and Sozoniuk, V. (2013). OECD/NEA study on the economics and market of small reactors. Nuclear Engineering and Technology, 45(6), 701-706. https://doi.org/10.5516/ NET.02.2013.517
Lommers, L.J., Shahrokhi, F., Mayer III, J.A., and Southworth, F.H. (2012). AREVA HTR concept for near-term deployment. Nuclear Engineering and Design, 251, 292-296. https://doi.org/10.1016/ j.nucengdes.2011.10.030

Lyman, E. (2013). Small Isn't Always Beautiful Safety, Security, and Cost Concerns about Small Modular Reactors.

Macintosh, A. (2007) Siting Nuclear Power Plants in Australia Where would they go?

Maqsood, I., Huang, G., Huang, Y., and Chen, B. (2005). ITOM: An interval-parameter two-stage optimization model for stochastic planning of water resources systems. Stochastic Environmental Research and Risk Assessment, 19(2), 125-133. https://doi.org/ 10.1007/s00477-004-0220-6

Margulies, T.S. (2004). Risk optimization: Siting of nuclear power electricity generating units. Reliability Engineering and System Safety, 86(3), 323-325. https://doi.org/10.1016/j.res s.2004.02.009

McCreath, D.R. and Diederichs, M.S. (1994). Assessment of near-field rock mass fracturing around a potential nuclear fuel waste repository in the Canadian Shield. International Journal of Rock Mechanics and Mining Sciences and geomechanics abstracts, 31(5), 457-470. https://doi.org/10.1016/0148-9062(94)9014 9-X

Mignacca, B., Locatelli, G., Alaassar, M., and Invernizzi, D.C. (2018). We never built small modular reactors (SMRs), but what do we know about modularization in construction? International Conference on Nuclear Engineering, 1, 1-10. https://doi.org/10.1115/ ICONE26-81604

Miyamoto, K., Inoue, Y., Iwakura, T., Takeda, H., Fuma, S., Yanagisawa, K., and Ishii, N. (2002). An application of a transfer model to the drainage system of tritium in a river basin in the vicinity of a nuclear site. Fusion Science and Technology, 41(3 II), 483-487. https://doi.org/10.13182/FST02-A22636

Naterer, G.F., Ibrahim, D., and Calin, Z. (2013). Worldwide nuclear energy research programs. Hydrogen Production from Nuclear Energy, 65-97. https://doi.org/10.10 07/978-1-4471-4938-5_3

Nian, V. (2017). The prospects of small modular reactors in Southeast Asia. Progress in Nuclear Energy, 98, 131-142. https://doi.or g/10.1016/j.pnucene.2017.03.010

Nian, V. and Zhong, S. (2020). Economic feasibility of flexible energy productions by small modular reactors from the perspective of integrated planning. Progress in Nuclear Energy, 118, 103106. https://doi.org/10.1016/j.pnucene.2019.103106

Openshaw, S. (1984). An evaluation of the safety characteristics of current and possible future nuclear power stations series. Journal of the Royal Statistical Society. 33(1), 133-142. https://doi.org/10. $2307 / 2987720$

Park, K.B. (2011). SMART: an early deployable integral reactor for multi-purpose applications Vienna, Austria.

Poudel, B., Joshi, K.A., and Gokaraju, R. (2018). Analysis for siting and sizing of a small modular reactor - A case study in Canada. 2018 20th National Power Systems Conference, NPSC 2018. IEEE, 1-6. https://doi.org/10.1109/NPSC.2018.8771710

Ramana, M.V., Hopkins, L.B., and Glaser, A. (2013). Licensing small modular reactors. Energy, 61, 555-564. https://doi.org/10.1016/j. energy.2013.09.010

Reyes, J.N. (2012). NuScale plant safety in response to extreme events. Nuclear Technology, 178(2), 153-163. https://doi.org/10.13182/ NT12-A13556

Rybach, L., Bucher, B., and Schwarz, G. (2001). Airborne surveys of Swiss nuclear facility sites. Journal of environmental radioactivity. 53(3), 291-300. https://doi.org/10.1016/S0265-931X(00) 00137-5

Salih, N.A.M., AL-Bakhat, Y.M.Z., ulmajeed Al-Rahmani, A.A., Murbat, O.M., Ameen, N.H., and Majed, N.A. (2018). Assessment of radiological air contamination for selected places at al-Tuwaitha nuclear site during winter and spring. Baghdad Science Journal, 15(3), 278-286. https://doi.org/10.21123/bsj.2018.15.3.0278

Sam-Aggrey, H. (2016). Opportunities and challenges related to the deployment of small modular reactors in mines in the Northern 
Territories of Canada. CNL Nuclear Review, 5(1), 143-153. https:// doi.org/10.12943/CNR.2015.00058

Shirvan, K., Ballinger, R., Buongiorno, J., Forsberg, C., Kazimi, M., and Todreas, N. (2016). Technology Selection for Offshore Underwater Small Modular Reactors. Nuclear Engineering and Technology. Elsevier B.V, 48(6), 1303-1314. https://doi.org/10.1016/ j.net.2016.06.002

Shrestha, R., Wagner, D., and Al-Anbagi, I. (2018). Fuzzy AHP-based siting of small modular reactors for power generation in the smart grid. 2018 IEEE Electrical Power and Energy Conference, 1-6. https://doi.org/10.1109/EPEC.2018.8598393

Siegel, J., Gilmore, E.A., Gallagher, N., and Fetter, S. (2018). An expert elicitation of the proliferation resistance of using Small Modular Reactors (SMR) for the expansion of civilian nuclear systems. Risk Analysis, 38(2), 242-254. https://doi.org/10.1111/ris a.12861

Spencer, J. and Loris, N.D. (2011). A Big Future for Small Nuclear Reactors? Heritage Foundation, 4999(2514).

Sun, C., Lyu, N., and Ouyang, X. (2014). Chinese public willingness to pay to avoid having nuclear power plants in the neighborhood. Sustainability, 6(10), 7197-7223. https://doi.org/10.3390/su6107197

Tan, Q., Huang, G.H., and Cai, Y.P. (2011). Radial interval chanceconstrained programming for agricultural non-point source water pollution control under uncertainty. Agricultural Water Management, 98(10), 1595-1606. https://doi.org/10.1016/j.agwat.2011.05. 013

Tanaka, Y. (2004). Major psychological factors determining public acceptance of the siting of nuclear facilities. Journal of Applied Social Psychology, 34(6), 1147-1165. https://doi.org/10.1111/j.15 59-1816.2004.tb02000.x

Terrapon-Pfaff, J., Dienst, C., König, J., and Ortiz, W. (2014). A crosssectional review: Impacts and sustainability of small-scale renewable energy projects in developing countries. Renewable and Sustainable Energy Reviews, 40, 1-10. https://doi.org/10.1016/j.rser. 2014.07.161

Tromans, I.J., Aldama-Bustos, G., Douglas, J., Lessi-Cheimariou, A., Hunt, S., Daví, M., and Robertson, C. (2019). Probabilistic seismic hazard assessment for a new-build nuclear power plant site in the UK. Bulletin of Earthquake Engineering, 17(1), 1-36. https:// doi.org/10.1007/ s10518-018-0441-6

Turner, K. (2002). Site Selection and Evaluation Criteria for an Early Site Permit Application.

Udiyani, P.M., Husnayani, I., and Sunaryo, G.R. (2018). Analysis of radiation safety for Small Modular Reactor (SMR) on PWR-100
MWe type. Journal of Physics: Conference Series, 962(1). https:// doi.org/10.1088/1742-6596/962/1/012035

Värri, K. and Syri, S. (2019). The possible role of modular nuclear reactors in district heating: Case Helsinki region. Energies, 12(11), 1-24. https://doi.org/10.3390/en12112195

Vegel, B. and Quinn, J.C. (2017). Economic evaluation of small modular nuclear reactors and the complications of regulatory fee structures. Energy Policy, 104, 395-403. https://doi.org/10.1016/ j.enpol.2017.01.043

Vujić, J., Bergmann, R.M., Škoda, R., and Miletić, M. (2012). Small modular reactors: Simpler, safer, cheaper? Energy, 45(1), 288-295. https://doi.org/10.1016/j.energy.2012.01.078

Wang, B., Liu, F., Zhang, C., Qiao, Y., Liu, Y., Yang, Y., and Shi, Q. (2013). Site selection considerations of spent nuclear fuel reprocessing plant in China. Energy Procedia, 39, 382-386. https://doi. org/10.1016/j.egypro.2013.07.226

Watson, M.B., Kammer, W.A., Langley, N.P., Selzer, L.A., and Beck, R.L. (1975). Underground nuclear power plant siting. Nuclear Engineering and Design, 33(3), 269-307. https://doi.org/10.1016/ 0029-5493(75)90001-1

Weng, S.Q., Huang, G.H., and Li, Y.P. (2010). An integrated scenariobased multi-criteria decision support system for water resources management and planning - A case study in the Haihe River Basin. Expert Systems with Applications, 37(12), 8242-8254. https:// doi.org/10.1016/j.eswa.2010.05.061

Wu, Y., Liu, F., Huang, Y., Xu, C., Zhang, B., Ke, Y., and Jia, W. (2020) A two-stage decision framework for inland nuclear power plant site selection based on GIS and type-2 fuzzy PROMETHEE II: Case study in China. Energy Science and Engineering, 1-21. https:// doi.org/10.1002/ese3.640

Yaar, I., Walter, A., Sanders, Y., Felus, Y., Calvo, R., and Hamiel, Y. (2016). Possible sites for future nuclear power plants in Israel. Nuclear Engineering and Design, 298, 90-98. https://doi.org/10.10 16/j.nucengdes.2015.12.005

Yu, H., Huang, G. H., An, C.J., and Wei, J. (2011). Combined effects of DOM extracted from site soil/compost and biosurfactant on the sorption and desorption of PAHs in a soil-water system. Journal of Hazardous Materials, 190(1-3), 883-890. https://doi.org/10.1016/j. jhazmat.2011.04.026

Zhang, Q., Guo, R., Zhang, C., Chen, X., and Wang, B. (2014). Radioactive airborne effluents and the environmental impact assessment of CAP1400 nuclear power plant under normal operation. Nuclear Engineering and Design, 280, 579-585. https://doi.org/ 10.1016/j.nucengdes.2014.09.014 